\title{
DEVELOPMENT AND APPLICATION OF AN ELECTRICAL BUZZ WIRE TO EVALUATE EYE-HAND COORDINATION AND OBJECT CONTROL SKILL IN CHILDREN: A FEASIBILITY STUDY
}

original paper

() Wroclaw University of Health and Sport Sciences

DOI: https://doi.org/10.5114/hm.2022.109072

\section{GUSTAVO JOSÉ LUVIZUTTO ${ }^{1}$, ANA CAROLINA BRUNO ${ }^{1}$, SABRINA FERREIRA DE OLIVEIRA ${ }^{1}$, MARISTELLA BORGES SILVA ${ }^{2}$, LUCIANE APARECIDA PASCUCCI SANDE DE SOUZA ${ }^{1}$}

${ }^{1}$ Department of Applied Physical Therapy, Institute of Health Sciences, Federal University of Triângulo Mineiro, Uberaba, Brazil

${ }^{2}$ Department of Physical Therapy, Faculty of Human Talent, Uberaba, Brazil

\section{ABSTRACT}

Purpose. There are many instruments to test children's motor coordination, but the problem is that none of them evaluates accuracy and precision during motor tasks. Therefore, the aim of the study was to develop and test the applicability of electrical buzz wire (EBW) as an instrument for assessing eye-hand coordination and object control skill in children, as well as to delimit the mean time and errors in tasks involving speed and/or accuracy.

Methods. The cross-sectional study involved 66 children (28 boys and 38 girls) aged 7-12 years. The variables evaluated were anthropometrics, hand dominance, and Movement Assessment Battery for Children (MABC-2). The outcomes were time (s) and error ( $n$ ) during 4 tasks while changing speed and wire loop size.

Results. The ANOVA analysis showed statistically significant differences in the time variable $[\mathrm{F}(4,502)=8.6155, p<0.001]$ and in the error $[\mathrm{F}(6,502)=69.209, p<0.001]$. The mean values of time and errors in each task were standardized after linear regression: 2.38 errors and 37 seconds in task 1; 3.2 errors and 35 seconds in task 2; 6.4 errors and 24 seconds in task 3; and 6.4 errors and 23.1 seconds in task 4. The error and time variables in EBW presented weak negative correlations with all MABC-2 domains.

Conclusions. EBW was developed; the time and errors with a comfortable speed were lower than with a high speed, regardless of the difficulty level. Time and error values were also standardized in this age group.

Key words: children, eye-hand coordination, motor skill, health evaluation, task performance, functional performance

\section{Introduction}

The evaluation of motor coordination in children is important to identify delays in motor development [1], treatment evolution [2], performance between genders [3], physical fitness [4, 5]. So, it can be useful in different settings: clinical, sports and physical education classes. Applying instruments and scales that contain playful and challenging principles is therefore an interesting approach. There are many instruments to test children's motor coordination, but there is no gold standard, especially to evaluate eye-hand coordination and object control skill [6]. Most of these instruments focus on identifying children with fundamental movement skill development disorders and are rather time-consuming [7].

The ludic principle can be mainly employed to assess the eye-hand coordination and object control skill in children. In this way, an electrical buzz wire (EBW) was built as an attractive therapeutic tool. Some authors have demonstrated the use of EBW to assess children's facial expression during errors [8], manual dexterity training [9], and attentional and neuropsychiatric deficits [10], but none investigated the accuracy and precision during eye-hand coordination and object control skill assessment in children.

Correspondence address: Gustavo José Luvizutto, Department of Applied Physical Therapy, Institute of Health Sciences, Federal University of Triângulo Mineiro, Vigário Carlos, $n^{\circ} 100,3^{\circ}$ andar, Sala 321, Bloco B, Bairro Abadia, Uberaba, Minas Gerais, Brazil, CEP: 38025-350, e-mail: gustavo.luvizutto@uftm.edu.br 
EBW is considered an easy-to-reproduce, low-cost, and ludic instrument. So, can it be used as an evaluation tool for eye-hand coordination, focusing on the accuracy and precision when performing the activity? There is one study involving eye-hand coordination and object control skill in adults based on children's toys [11], but none has applied EBW to assess object control skill in children, and there are no parameters of the task protocol in this population.

A child needs to develop a great motor repertoire, especially for tasks that require reach and hand grip [12]. These patterns can change and self-organize depending on different environments [13, 14]. The use of EBW allows an interaction between reach and grip in several trajectories and challenges, and the child constantly needs to adapt the movement patterns of the upper limb, as well as the task speed. In addition, the instrument provides visual and auditory cues that require more attention during the performance. The use of EBW may reflect motor skills that the child performs in their usual environment.

On the basis of this background, we highlighted the relevance of testing eye-hand coordination and object control skill by using an instrument with a high level of practical feasibility. Therefore, the aim of the study was to develop and test the applicability of EBW as an instrument for assessing eye-hand coordination and object control skill in children, as well as to delimit the mean time and errors in tasks involving speed and/or accuracy. The hypotheses of this study were as follows: (1) EMW allows to evaluate the accuracy and precision of object control skill; (2) tasks involving higher speed decrease the time and increase errors; (3) tasks involving higher accuracy increase the time and decrease errors.

\section{Material and methods}

Study design, setting, and participants

This was a cross-sectional study with a convenience sample of 66 children ( 28 boys and 38 girls) aged 7-12 years, of both sexes, and regularly enrolled at school. The children were recruited at a public school of Uberaba (Minas Gerais, Brazil) between March 2018 and July 2019.

\section{Eligibility criteria}

The inclusion criteria involved: absence of motor, neurological, or cognitive impairments, age 7-12 years, standard score $\geq 8$ in the Movement Assessment Bat- tery for Children (MABC-2), and no use of any prescription medications. We excluded children who did not conclude the tests at any moment.

\section{Data collection setting}

The collections were carried out in the school environment, in a reserved room, without noise, during a break from classes. Two independent observers accompanied the collections. There was a warm-up period with EBW (1 minute of EBW free exploration was allowed).

\section{Data sources and measurement}

\section{Anthropometric variables}

Body mass was measured with digital scales (Filizola $\left.^{\circledR}\right)$, and height with a stadiometer (Welmy ${ }^{\circledR}$ ). Body mass index (BMI) was calculated in accordance with the Quetelet equation $\left(\mathrm{BMI}=\right.$ body mass $/$ height $\left.^{2}\right)$ by using body mass measured in kilograms and height measured in meters. Upper arm length was determined on the left side of the subject.

\section{Lateral dominance}

The Harris test of lateral dominance was used to establish each child's dominant hand. The test appears to be the one most often used in research studies determining lateral dominance. It is easily administered and usually turns out enjoyable to the subjects. The Harris test is validated for children and the reliability for the 4 hand dominance tasks equals 0.89 [15].

\section{The Movement Assessment Battery for Children, $2^{\text {nd }}$ edition}

This test is used to identify motor disorders in children aged 3-16 years [16]. The MABC-2 protocol consists of manual dexterity, aim and catch, and static and dynamic balancing tests. It was applied just one time, in accordance with the instrument recommendation. The score ranges from 1 to 19 for each item, and for each value, there is a corresponding percentage, which can range from $0.1 \%$ to $99.9 \%$ [17]. A score equal to or smaller than the $5^{\text {th }}$ percentile or 8 standard score is the cut-off point for motor difficulties in coordination [18]. The MABC-2 used in this research was original and complete, and was provided by the Federal University of São Carlos. The internal consistency for MABC-2 equalled $\alpha=0.90$. The test-re- 
test reliability for the total score was excellent, with an intraclass correlation coefficient of 0.97 in children $[19,20]$.

\section{Buzz wire coordination test}

An EBW coordination evaluation system was developed by researchers from the Biomechanics and Motor Control Laboratory of Federal University of Triângulo Mineiro, on the basis of children's toys and the instrument proposed by Read et al. [11]. The device measurements are specified in Figure 1. As can be observed in Figure 2, one must guide a wire loop around a complicated wire track without touching the loop to the track, using binocular vision. A buzzing noise indicates whenever contact is made.

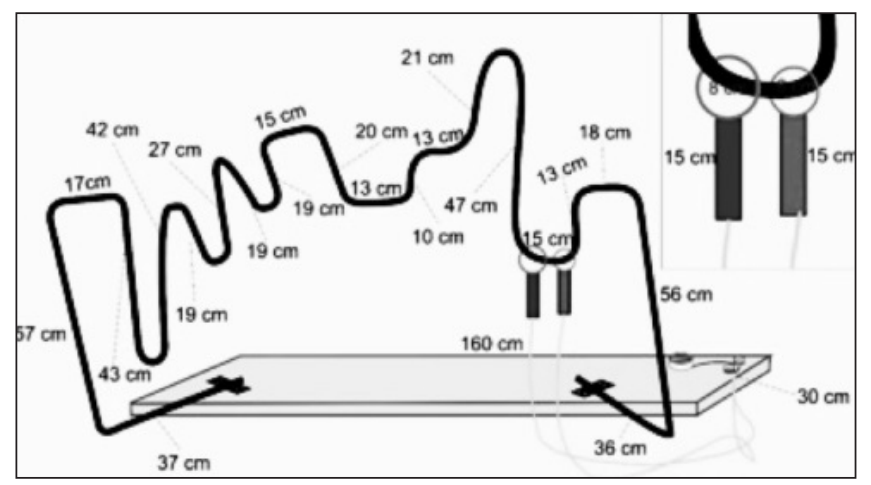

Figure 1. Electrical buzz wire

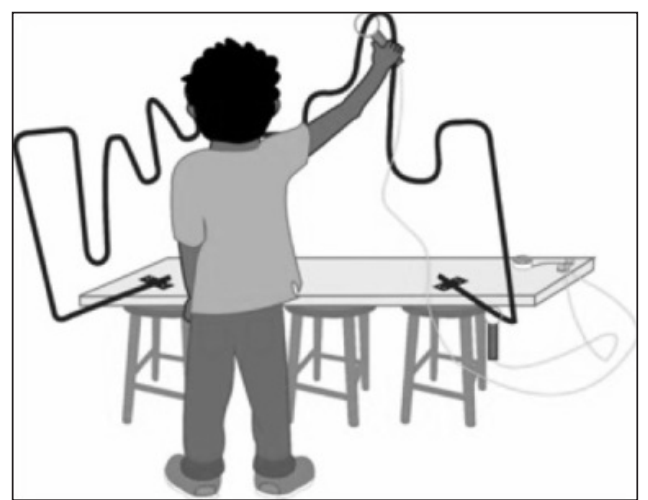

Figure 2. Illustration of a child executing the task
The buzzing noises indicated errors and they were registered by 2 independent evaluators. The task time was recorded with a stopwatch $\left(\mathrm{Akso}^{\circledR}\right)$. All tasks followed the commands presented in Table 1.

Four tasks were performed with 2 commands and 2 wire loop sizes (Table 1). Five trials were conducted in each task. A 1-minute rest was applied between the trials. For data analysis, the first trial was eliminated and the mean values of error and time of the other trials were considered.

The index of task difficulty was proposed by Fitts's law [21]:

$$
\mathrm{t}=\mathrm{a}+\mathrm{b} \cdot \log 2(\mathrm{~d} / \mathrm{w})
$$

where $\mathrm{t}$ - index of difficulty, $\mathrm{a}$ - fixes cost portion, $\mathrm{b}$ control rate, $\mathrm{d}$ - distance from the starting point to EBW, and $\mathrm{w}$ - width of the wire loop. In tasks 1 and 3, the index of difficulty was 1.34, and in tasks 2 and 4 , the index was 1.42 .

\section{Sample size}

The sample size calculation involved the moderate correlation coefficient $(r=-0.4)$ between EBW time and error and MABC-2 scale considering the statistical significance of 0.05 (95\%), type II error of 0.1 (90\%), and effect size of 0.63 . The sample size was calculated by using the PASS 13 application. The minimum sample size for this study was 61 children.

\section{Statistical analysis}

Descriptive statistics were used to describe the characteristics of the participants. Mean and standard deviation values were reported for continuous variables, and number and percent were provided for categorical variables. The Shapiro-Wilk test was performed to verify the normality of the data. One-way ANOVA was applied for error and time variables in EBW, and posthoc Tukey's test for multiple comparisons between the tasks. Linear regression was used to establish the relationship between error and time during each task.

Table 1. Tasks and commands during the electrical buzz wire test

\begin{tabular}{ccl}
\hline Task & Wire loop & Command \\
\hline 1 & $8.0 \mathrm{~cm}$ & Do the test in a comfortable speed, as accurately as possible. Try not to touch the ring in the buzz wire \\
2 & $6.0 \mathrm{~cm}$ & Do the test in a comfortable speed, as accurately as possible. Try not to touch the ring in the buzz wire \\
3 & $8.0 \mathrm{~cm}$ & Do the test as fast and accurately as possible. Try not to touch the ring in the buzz wire \\
4 & $6.0 \mathrm{~cm}$ & Do the test as fast and accurately as possible. Try not to touch the ring in the buzz wire \\
\hline
\end{tabular}


Spearman's correlation served to verify the associations between error and time variables in EBW and MABC-2 (total and domain scores). The inter-rater reliability was determined by Cohen's kappa coefficient $(\kappa)$. Statistical significance of the results was accepted at $p<0.05$. All data were analysed with the IBM SPSS Statistics for Windows (version 23.0; IBM Corp., Armonk, NY, USA).

\section{Ethical approval}

The research related to human use has complied with all the relevant national regulations and institutional policies, has followed the tenets of the Declaration of Helsinki, and has been approved by the Human Research Ethics Committee of the Federal University of Triângulo Mineiro.

\section{Informed consent}

Informed consent has been obtained from the parents of all individuals included in this study.

\section{Results}

The demographic variables and performance in the EBW tasks are shown in Table 2. The inter-rater reliability was 0.86 for error and 0.67 for time.

The ANOVA analysis revealed a statistically significant difference in the time variable $[F(4,502)=8.6155$, $p<0.001]$ and in the number of errors $[\mathrm{F}(6,502)=$ $69.209, p<0.001]$. The post-hoc analysis demonstrated that the mean time in task 1 (wire loop with $8 \mathrm{~cm}$ and low speed) was statistically significantly different when compared with the mean time in task 3 (wire loop with $8 \mathrm{~cm}$ and high speed) (mean difference [MD]: 10.3; CI: -11.72 to $-7.557 ; p<0.0001$ ) and task 4 (wire loop with $6 \mathrm{~cm}$ and high speed) (MD: 12.2; CI: -12.65 to $-8.497 ; p<0.0001)$. A statistically significant differ-
Table 2. Demographic variables and task performance in the sample $(n=66)$

\begin{tabular}{|c|c|c|}
\hline Parameters & Average & $S D$ \\
\hline Age (years) & 9.50 & 1.721 \\
\hline Sex (male:female) & \multicolumn{2}{|c|}{$28: 38$} \\
\hline Lateral dominance (right:left) & \multicolumn{2}{|c|}{$56: 10$} \\
\hline Body mass index $\left(\mathrm{kg} / \mathrm{m}^{2}\right)$ & 17.67 & 4.438 \\
\hline Upper arm length $(\mathrm{cm})$ & 54.70 & 2.997 \\
\hline \multicolumn{3}{|l|}{ Task 1} \\
\hline Time (s) & 33.70 & 4.307 \\
\hline Errors (number of buzzing noises) & 2.52 & 1.850 \\
\hline \multicolumn{3}{|l|}{ Task 2} \\
\hline Time (s) & 35.05 & 5.290 \\
\hline Errors (number of buzzing noises) & 2.31 & 1.870 \\
\hline \multicolumn{3}{|l|}{ Task 3} \\
\hline Time (s) & 24.02 & 4.560 \\
\hline Errors (number of buzzing noises) & 6.45 & 2.359 \\
\hline \multicolumn{3}{|l|}{ Task 4} \\
\hline Time (s) & 23.11 & 4.202 \\
\hline Errors (number of buzzing noises) & 6.45 & 2.818 \\
\hline
\end{tabular}

ence was observed between the mean time in task 2 (wire loop with $6 \mathrm{~cm}$ and low speed) and that in task 3 (MD: 8.8; CI: 9.042 to $13.2 ; p<0.0001$ ) and task 4 (MD: 10.7; CI: 9.982 to $14.14 ; p<0.0001$ ). In the error variable, it was noted that the mean error in task 1 showed a statistically significant difference when compared with the mean error in task 3 (MD: -5.1; CI: -4.921 to $-2.898 ; p<0.0001$ ) and task 4 (MD: -5.4 ; CI: -4.951 to $-2.928 ; p<0.0001)$. The mean error in task 2 presented a statistically significant difference when compared with the mean error in task 3 (MD: -5.6; CI: -5.133 to $-3.11 ; p<0.0001$ ) and task 4 (MD: -5.8 ; CI: -5.163 to $-3.14 ; p<0.0001$ ) (Figure 3).

B

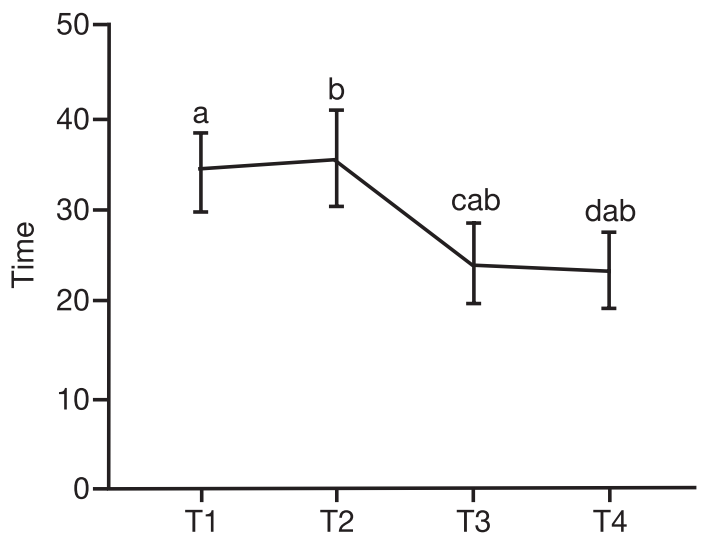

Figure 3. Comparison of error numbers (A) and time (B) between tasks in the electrical buzz wire test. The same letter indicates a statistically significant difference $(p<0.05)$ 
From the data obtained in the linear regression to establish the relation between error and time during each task in the EBW test, equations were created for normalized values in this population:

$$
\begin{aligned}
& \text { Error }=-0.31+0.08 \times \text { time }(\text { for task } 1) \\
& \text { Error }=2.78+0.013 \times \text { time }(\text { for task } 2) \\
& \text { Error }=9.11-0.11 \times \text { time }(\text { for task } 3) \\
& \text { Error }=7.57-0.048 \times \text { time }(\text { for task } 4)
\end{aligned}
$$

The mean values of time obtained in each task were used to establish the number of normal errors in the EBW test in the population: 2.38 errors for 37 seconds in task 1; 3.2 errors for 35 seconds in task 2; 6.4 errors for 24 seconds in task 3; and 6.4 errors for 23.1 seconds in task 4.

The error and time variables in EBW presented weak correlations with all MABC-2 domains. The correlations are shown in Supplementary Table 1.

\section{Discussion}

EBW is an applicable tool to investigate object control skill in children aged 7-12 years. With the equations based on the mean execution times in the tasks, it was possible to relate the number of errors with the time of execution for this population. The findings indicate that our hypotheses were partially confirmed because a higher speed was related to a greater number of errors in EBW, independently of the level of difficulty determined by the size of the wire loop.

Some motor coordination tasks require the volunteer to perform with speed and accuracy. We often observe a speed-accuracy trade-off phenomenon. Fitts's law has played an important role in quantifying the speed-accuracy trade-off. According to Fitts [21], the time to do some activity is directly related to the speed used. With the inverse relation of velocity and accuracy of a movement, it leads us to conclude that with higher speeds, the accuracy is impaired [22]. Our methodological approach allowed us to visualize the differences between the tasks. In tasks 3 and 4, there was a change of strategy: priority of speed over accuracy, showing a higher number of errors and shorter execution time in EBW. In tasks 1 and 2, the chosen strategy was priority of accuracy over speed, implying a low number of errors and higher time of execution.

In the present study, we did not find a relationship between the wire loop sizes and number of errors in the tasks. However, we can assume that the type of control used was the cyclic or open-loop control in all tasks. This type of control results from pre-planned movement commands that are stored and then activated in the central nervous system (CNS). In 1960, Henry and Rogers [23] described the memory drum theory, which postulates that motor coordination patterns are stored in the form of neural patterns in the higher centres of the CNS, and predicts that simple reaction time increases with task complexity [23, 24]. In contrast, there are movements characterized as less cyclical or closed-loop controlled; these are thought to result from an initial movement command generated in the CNS that is subsequently adjusted or corrected as movement errors are detected [25-27]. Unfortunately, in our study, there was no task to activate this type of control, and maybe this is the cause of the same responses in the different wire loop sizes.

We highlight the importance of EBW association with manual dexterity of MABC-2, as there are specific coordination assessment tasks. We found a weak association $(r<0.5)$ between error/time in EBW and the MABC-2 manual dexterity and aim and catch items. According to French et al. [28], MABC-2, while useful in clinical settings and assessment of individuals, might not be as efficient for quantitative research and larger numbers of participants. Alves Bakke et al. [29] emphasized the divergence in the multidimensionality of MABC-2. This can compromise the practical utility of the test since the capacity to evaluate motor performance as predicted was not confirmed. The results of its subscales (manual dexterity, aiming and catching, and balance) should be interpreted with caution as they may be prone to errors.

We also did not use perceptual, visual, or cognitive scales, which can be considered a limitation of the present study. Despite these limitations, which can be solved in future studies, the tool used is easy to apply, constructed of low-cost material, and playful for the population. The instrument allows evaluation of movement control to guide a wire loop around a complicated wire track. During this task, controlled movements are necessary, such as hand grip, ulnar and radial deviations, wrist flexion and extension, pronation and supination of the forearm, and other shoulder and elbow movements. These movements are essential for the object control skill, including all necessary variables to guarantee a coordinated movement. We can infer the possibility of EBW use in other age ranges and also in specific disabilities.

\section{Conclusions}

EBW was developed and the results showed that the time and number of errors with a comfortable speed 
were lower when compared with high speed, regardless of the level of difficulty. Time and error values were also standardized in this age group (7-12 years). EBW is an interesting tool that could be more investigated and incorporated into the evaluation of eyehand coordination and object control skill in children.

\section{Disclosure statement}

No author has any financial interest or received any financial benefit from this research.

\section{Conflict of interest}

The authors state no conflict of interest.

\section{References}

1. Vaivre-Douret L, Burnod Y. Development of a global motor rating scale for young children ( $0-4$ years) including eye-hand grip coordination. Child Care Health Dev. 2001;27(6):515-534; doi: 10.1046/j.1365-2214.2001. 00221.x.

2. Hsu L-Y, Jirikowic T, Ciol MA, Clark M, Kartin D, McCoy SW. Motor planning and gait coordination assessments for children with developmental coordination disorder. Phys Occup Ther Pediatr. 2018;38(5):562574; doi: 10.1080/01942638.2018.1477226.

3. Barnett LM, van Beurden E, Morgan PJ, Brooks LO, Beard JR. Gender differences in motor skill proficiency from childhood to adolescence: a longitudinal study. Res Q Exerc Sport. 2010;81(2):162-170; doi: 10.1080/0270 1367.2010.10599663.

4. Haga M. The relationship between physical fitness and motor competence in children. Child Care Health Dev. 2008;34(3):329-334; doi: 10.1111/j.1365-2214.2008. 00814.x.

5. Olesen LG, Kristensen PL, Ried-Larsen M, Grøntved A, Froberg K. Physical activity and motor skills in children attending 43 preschools: a cross-sectional study. BMC Pediatr. 2014;14:229; doi: 10.1186/1471-243114-229.

6. Ferreira L, Gabbard C, Lopes Vieira JL, Norralia da Silva P, Cheuczuk F, Ferreira da Rocha F, et al. Reconsidering the use of cut-off scores: DCDQ - Brazil. Rev Bras Med Esporte. 2019;25(4):344-348; doi: 10.1590/1517869220192504183194.

7. Platvoet S, Faber IR, de Niet M, Kannekens R, Pion J, Elferink-Gemser MT, et al. Development of a tool to assess fundamental movement skills in applied settings. FrontEduc. 2018;3:75; doi: 10.3389/feduc.2018.00075.

8. Halligan SL, Cooper PJ, Fearon P, Wheeler SL, Crosby M, Murray L. The longitudinal development of emotion regulation capacities in children at risk for externalizing disorders. Dev Psychopathol. 2013;25(2):391406; doi: 10.1017/S0954579412001137.

9. Budini F, Lowery MM, Hutchinson M, Bradley D, Conroy L, De Vito G. Dexterity training improves manual precision in patients affected by essential tremor. Arch
Phys Med Rehabil. 2014;95(4):705-710; doi: 10.1016/j. apmr.2013.11.002.

10. Custance DM, Mayer JL, Kumar E, Hill E, Heaton PF. Do children with autism re-enact object movements rather than imitate demonstrator actions? Autism Res. 2014;7(1):28-39; doi: 10.1002/aur.1328.

11. Read JCA, Begum SF, McDonald A, Trowbridge J. The binocular advantage in visuomotor tasks involving tools. Iperception. 2013;4(2):101-110; doi: 10.1068/i0565.

12. Adolph KE, Franchak JM. The development of motor behavior. Wiley Interdiscip Rev Cogn Sci. 2017;8(1-2): e1430; doi: 10.1002/wcs.1430.

13. Gibson JJ. The ecological approach to visual perception. Boston: Houghton Mifflin; 1979.

14. De Barros KMFT, Gusmão Câmara Fragoso A, Lemos Bezerra de Oliveira A, Cabral Filho JE, Manhães de Castro R. Do environmental influences alter motor abilities acquisition? A comparison among children from day-care centers and private schools. Arq Neuropsiquiatr. 2003;61(2A):170-175; doi: 10.1590/s0004282x2003000200002.

15. Belmont L, Birch HG. Lateral dominance, lateral awareness, and reading disability. Child Dev. 1965;36(1):5771; doi: 10.2307/1126780.

16. Valentini NC, Ramalho MH, Oliveira MA. Movement Assessment Battery for Children-2: translation, reliability, and validity for Brazilian children. Res Dev Disabil. 2014;35(3):733-740; doi: 10.1016/j.ridd.2013.10.028.

17. Da Silva Ramalho MH, Valentini NC, Muraro CF, Gadens R, Carvalho Nobre G. Validation for Portuguese language: Movement Assessment Battery for Children checklist [in Portuguese]. Motriz. 2013;19(2):423-431; doi: 10.1590/S1980-65742013000200019.

18. Capistrano R, Pinheiro Ferrari E, Portes de Souza L, Silva Beltrame T, Cardoso FL. Concurrent validation of the MABC-2 motor tests and MABC-2 checklist according to the Developmental Coordination Disorder Questionnaire-BR. Motriz. 2015;21(1):100-106; doi: 10.1590/S1980-65742015000100013.

19. Schoemaker MM, Niemeijer AS, Flapper BCT, SmitsEngelsman BCM. Validity and reliability of the Movement Assessment Battery for Children-2 checklist for children with and without motor impairments. Dev Med Child Neurol. 2012;54(4):368-375; doi: 10.1111/j.14698749.2012.04226.x.

20. Wuang Y-P, Su J-H, Su C-Y. Reliability and responsiveness of the Movement Assessment Battery for Children-Second Edition test in children with developmental coordination disorder. Dev Med Child Neurol. 2012; 54(2):160-165; doi: 10.1111/j.1469-8749.2011.04177.x.

21. Fitts PM. The information capacity of the human motor system in controlling the amplitude of movement. J Exp Psychol. 1954;47(6):381-391; doi: 10.1037/h00 55392.

22. Wang C, Boyle JB, Dai B, Shea CH. Do accuracy requirements change bimanual and unimanual control processes similarly? Exp Brain Res. 2017;235(5):14671479; doi: 10.1007/s00221-017-4908-5. 


\section{HUMAN MOVEMENT}

G.J. Luvizutto et al., Electrical buzz wire development

23. Henry FM, Rogers DE. Increased response latency for complicated movements and a "memory drum" theory of neuromotor reaction. Res Quart Am Assoc Health Phys Educ Recreat. 1960;31:448-458; doi: 10.1080/ 10671188.1960.10762052.

24. Anson JG. Memory drum theory: alternative tests and explanations for the complexity effects on simple reaction time. J Mot Behav. 1982;14(3):228-246; doi: 10.1080/ 00222895.1982.10735276.

25. Buchanan JJ, Park J-H, Shea CH. Systematic scaling of target width: dynamics, planning, and feedback. Neurosci Lett. 2004;367(3):317-322; doi: 10.1016/j.neulet.2004.06.028.

26. Buchanan JJ, Ryu YU. One-to-one and polyrhythmic temporal coordination in bimanual circle tracing. J Mot
Behav. 2006;38(3):163-184; doi: 10.3200/JMBR.38.3. 163-184.

27. Buchanan JJ. Flexibility in the control of rapid aiming actions. Exp Brain Res. 2013;229(1):47-60; doi: 10.1007/ s00221-013-3589-y.

28. French B, Sycamore NJ, McGlashan HL, Blanchard CCV, Holmes NP. Ceiling effects in the Movement Assessment Battery for Children-2 (MABC-2) suggest that non-parametric scoring methods are required. PLoS One. 2018; 13(6):e0198426; doi: 10.1371/journal.pone.0198426.

29. Alves Bakke H, Sarinho SW, Cattuzzo MT. Study of the multidimensionality of the MABC-2 (7 to 10 years old) in children from the metropolitan region of Recife-PE. J Phys Educ. 2018;29:e2939; doi: 10.4025/jphyseduc. v29i1.2939.

\section{Supplementary}

Table 1. Associations between error and time variables in electrical buzz wire and Movement Assessment Battery for Children (total and domain scores)

\begin{tabular}{|c|c|c|c|c|c|c|c|c|}
\hline \multirow[b]{2}{*}{ Domains } & \multicolumn{2}{|c|}{ Task 1} & \multicolumn{2}{|c|}{ Task 2} & \multicolumn{2}{|c|}{ Task 3} & \multicolumn{2}{|c|}{ Task 4} \\
\hline & Time (s) & $\begin{array}{c}\text { Error } \\
\text { (number } \\
\text { of buzzing } \\
\text { noises) }\end{array}$ & Time (s) & $\begin{array}{c}\text { Error } \\
\text { (number } \\
\text { of buzzing } \\
\text { noises) }\end{array}$ & Time (s) & $\begin{array}{c}\text { Error } \\
\text { (number } \\
\text { of buzzing } \\
\text { noises) }\end{array}$ & Time (s) & $\begin{array}{c}\text { Error } \\
\text { (number } \\
\text { of buzzing } \\
\text { noises) }\end{array}$ \\
\hline Manual dexterity & $\begin{array}{r}r=-0.05 \\
p=0.67\end{array}$ & $\begin{array}{r}r=-0.06 \\
p=0.58\end{array}$ & $\begin{array}{r}r=-0.12 \\
p=0.30\end{array}$ & $\begin{array}{c}r=-0.27 \\
p=0.02 *\end{array}$ & $\begin{array}{c}r=-0.12 \\
p=0.34\end{array}$ & $\begin{array}{r}r=-0.12 \\
p=0.34\end{array}$ & $\begin{array}{r}r=-0.19 \\
p=0.12\end{array}$ & $\begin{array}{r}r=-0.05 \\
p=0.64\end{array}$ \\
\hline $\begin{array}{l}\text { Aiming } \\
\text { and catching }\end{array}$ & $\begin{array}{r}r=-0.17 \\
p=0.17\end{array}$ & $\begin{array}{r}r=-0.05 \\
p=0.69\end{array}$ & $\begin{array}{r}r=-0.11 \\
p=0.38\end{array}$ & $\begin{array}{r}r=-0.12 \\
p=0.35\end{array}$ & $\begin{array}{r}r=-0.06 \\
p=0.63\end{array}$ & $\begin{array}{r}r=-0.22 \\
p=0.07\end{array}$ & $\begin{array}{r}r=-0.05 \\
p=0.68\end{array}$ & $\begin{array}{r}r=-0.07 \\
p=0.58\end{array}$ \\
\hline Balance & $\begin{array}{r}r=-0.10 \\
p=0.42\end{array}$ & $\begin{array}{r}r=-0.05 \\
p=0.68\end{array}$ & $\begin{array}{r}r=-0.05 \\
p=0.67\end{array}$ & $\begin{array}{r}r=-0.05 \\
p=0.65\end{array}$ & $\begin{array}{r}r=-0.17 \\
p=0.17\end{array}$ & $\begin{array}{r}r=-0.01 \\
p=0.93\end{array}$ & $\begin{array}{r}r=-0.18 \\
p=0.13\end{array}$ & $\begin{array}{r}r=-0.02 \\
p=0.90\end{array}$ \\
\hline Total & $\begin{array}{r}r=-0.17 \\
p=0.95\end{array}$ & $\begin{array}{r}r=-0.05 \\
p=0.70\end{array}$ & $\begin{array}{r}r=-0.11 \\
p=0.26\end{array}$ & $\begin{array}{l}r=-0.30 \\
p=0.01 *\end{array}$ & $\begin{array}{c}r=-0.22 \\
p=0.04^{*}\end{array}$ & $\begin{array}{r}r=-0.19 \\
p=0.04\end{array}$ & $\begin{array}{l}r=-0.35 \\
p=0.004^{*}\end{array}$ & $\begin{array}{c}r=-0.06 \\
p=0.91\end{array}$ \\
\hline
\end{tabular}

* statistically significant 